\title{
Emergency department visual urinalysis versus laboratory urinalysis
}

\author{
James C. Worrall, MD
}

\section{ABSTRACT}

Objective: The primary objective of this study was to compare the results of nurse-performed urinalysis (NPU) interpreted visually in the emergency department (ED) with laboratoryperformed urinalysis (LPU) interpreted by reflectance photometry.

Methods: This was a prospective observational study based on a convenience sample from my emergency practice. Emergency nurses, who were unaware of the study, performed usual dipstick analysis before sending the same urine sample to the laboratory for testing.

Results: Of 140 urinalyses performed during the study period, 124 were suitable for analysis. When compared with the reference standard LPU, the NPU had an overall sensitivity of $100 \%$ (95\% confidence interval [Cl] $95 \%-100 \%$ ) and a specificity of $49 \%(95 \% \mathrm{Cl} 33 \%-65 \%)$ for the presence of any 1 of blood, leukocyte esterase, nitrites, protein, glucose or ketones in the urine. Of 20 falsely positive NPUs, 18 were a result of the nurse recording 1 or more components as "trace" positive. Conclusion: Although NPU does not yield identical results to LPU, a negative LPU is expected when the initial NPU in the ED is negative.

Keywords: urinalysis, emergency department, point-of-care testing, laboratory delays

\section{RÉSUMÉ}

Objectif : L'objectif premier de cette étude était de comparer les résultats d'analyses d'urine interprétées visuellement par les infirmières (AUI) à l'urgence avec ceux d'analyses d'urine effectuées en laboratoire (AUL), interprétées par photométrie par réflectance.

Méthodes : Cette étude prospective d'observation était basée sur un échantillon de commodité du service d'urgence où je travaille et réalisée à l'insu des infirmières. Celles-ci ont effectué les analyses d'urine habituelles par bandelettes, avant d'envoyer le même échantillon d'urine au laboratoire aux fins d'analyse.
Résultats : Des 140 analyses d'urine effectuées pendant la période de l'étude, 124 convenaient à l'analyse. Comparativement à I'étalon de référence de I'AUL, les AUI avaient une sensibilité globale de $100 \%$ (intervalle de confiance [IC] à $95 \%$ de 95 à $100 \%$ ) et une spécificité de $49 \%$ (de 33 à $65 \%$ ) pour la présence dans les urines d'un des éléments suivants : sang, estérases leucocytaires, nitrites, protéines, glucose ou corps cétoniques. Des 20 AUI faussement positives, 18 l'étaient parce qu'une infirmière avait noté qu'il y avait des " traces " d'un élément ou plus.

Conclusion : Bien que les résultats de I'AUI ne soient pas identiques à ceux de l'AUL, on s'attend à ce que les résultats de I'AUL soient négatifs lorsque ceux de I'AUI initiale, faite au service d'urgence, le sont.

\section{INTRODUCTION}

The urinalysis is one of the most frequently performed tests in the emergency department (ED). However, not all urinalyses are performed in the same way. They are commonly performed in the ED by nurses as a point-of-care test using a dipstick reagent strip, and interpreted visually. In other centres, urine specimens are sent to the laboratory where reflectance photometry may be used. Despite substantial differences between these 2 approaches in turnaround time, only 1 pilot study has directly compared urinalyses performed in the ED with those performed in the laboratory. ${ }^{1}$

The primary objective of this study was to measure the performance of a nurse-performed urinalysis (NPU), which was performed by ED nurses and interpreted by visual comparison with the colour legend on the dipstick container, and compare the results with a gold standard laboratory-performed urinalysis (LPU), interpreted using reflectance photometry. Urine microscopy was not studied.

From the Department of Emergency Medicine, University of Ottawa, Ottawa, Ont. and the Department of Emergency Medicine, Cornwall Community Hospital, Cornwall, Ont.

Submitted Aug. 19, 2008; Revised Feb. 23, 2009; Accepted Mar. 9, 2009

This article has been peer reviewed. 


\section{METHODS}

This study took place in the ED of the Cornwall Community Hospital, a community hospital with more than 30000 visits annually. I prospectively collected a convenience sample from my own practice. Any patient for whom, in the physician's opinion, a urinalysis was indicated was eligible for inclusion in the study. I collected the data between March and June 2006. The patients and nurses were not aware of the study. The hospital ethics committee approved the study without need for patient consent.

Nurse-performed urinalyses were performed by ED nurses, who received no special instruction before this study. All nurses in this ED frequently perform dipstick urinalyses as a basic competency. Spontaneous or catheterized urine specimens were collected into sterile urine containers. Nurses performed urinalyses using a Bayer Multistix 8 SG urine dipstick, and recorded results in the ED chart. No attempt was made to measure interobserver variability. A porter or a laboratory technician transported the same urine specimens to the laboratory for testing using the same type of dipstick. Laboratory technicians analyzed the specimens using a Bayer Clinitek 500 urine chemistry analyzer. The laboratory staff were not aware of the NPU results. Delay in receiving the LPU results was not measured, but typically ranged from 60 to 120 minutes in this ED.

I recorded the following data for all NPUs and LPUs: indication for urinalysis, and presence of blood, leukocyte esterase, nitrites, protein, ketones and glucose. I recorded only the patient's chart number to link the NPUs and LPUs, and did not record other personal or identifying data, including final diagnosis. I considered

\begin{tabular}{|lc|}
\hline $\begin{array}{l}\text { Table 1. Indications for urinalysis among } \\
\text { 124 urine specimens included in the study }\end{array}$ \\
\hline Indication & No. of specimens \\
\hline Abdominal pain & 50 \\
Fever & 15 \\
Urinary symptoms & 12 \\
Pregnancy & 5 \\
Back pain & 5 \\
Genital symptoms & 5 \\
Weakness & 4 \\
Confusion & 2 \\
Edema & 2 \\
Other & 7 \\
Unrecorded & 17 \\
\hline
\end{tabular}

the LPU to represent the reference standard against which NPUs were compared.

I calculated confidence intervals (CIs) around rates using the Wilson method for binomial CIs with continuity correction.

\section{RESULTS}

I collected 140 urine specimens from 140 patients during the study period. Of these, 8 specimens did not have an LPU because the specimen was either lost or not sent to the laboratory after the NPU. Seven specimens did not have an NPU because the specimen was sent to the laboratory before the NPU was done. One further specimen was grossly bloody, and the laboratory reported it as "noninterpretable." This left 124 specimens for analysis (Table 1 ).

Of the 124 LPUs, 85 (69\%) were positive for at least 1 of the following: blood, leucocyte esterase, nitrites, protein, glucose or ketones. The NPUs had an overall sensitivity of $100 \%(95 \%$ CI $95 \%-100 \%)$ and a specificity of $49 \%$ (95\% CI 33\%-65\%) for any positive finding (Table 2). Of the 20 false positives, 18 were cases where the nurse recorded 1 or more components as "trace" positive.

\begin{tabular}{|c|c|c|}
\hline \multicolumn{3}{|c|}{$\begin{array}{l}\text { Table 2. Diagnostic accuracy of urinalysis } \\
\text { performed by emergency nurses } \\
\text { compared with hospital laboratory* }\end{array}$} \\
\hline \multirow[b]{2}{*}{ NPU } & \multicolumn{2}{|c|}{ LPU } \\
\hline & Any positive & All negative \\
\hline Any positive & 85 & 20 \\
\hline All negative & 0 & 19 \\
\hline \multicolumn{3}{|c|}{$\begin{array}{l}\mathrm{Cl}=\text { confidence interval; } \mathrm{LPU}=\text { laboratory-performed } \\
\text { urinalysis; NPU = nurse-performed urinalysis. } \\
\text { * The sensitivity was } 100 \%(95 \% \mathrm{Cl} 95 \%-100 \%) \text {, the } \\
\text { specificity was } 49 \%(95 \% \mathrm{Cl} 33 \%-65 \%) \text {, the positive } \\
\text { predictive value was } 81 \%(95 \% \mathrm{Cl} 72 \%-88 \%) \text { and the } \\
\text { negative predictive value was } 100 \%(95 \% \mathrm{Cl} 79 \%-100 \%) \text {. }\end{array}$} \\
\hline
\end{tabular}

Table 3. Diagnostic accuracy for nurse-performed urinalysis on each component of urinalysis compared with laboratoryperformed urinalysis

\begin{tabular}{|c|c|c|c|c|c|c|}
\hline \multirow{2}{*}{$\begin{array}{l}\text { Test; } \\
\text { result }\end{array}$} & \multicolumn{6}{|c|}{ No. of specimens } \\
\hline & Blood & d Leukocytes & Nitrites & Protein & Ketones & s Glucose \\
\hline $\begin{array}{l}\text { LPU; } \\
\text { positive }\end{array}$ & 61 & 23 & 9 & 37 & 26 & 4 \\
\hline NPU; TP & 60 & 21 & 6 & 35 & 19 & 1 \\
\hline NPU; FN & 1 & 2 & 3 & 2 & 7 & 3 \\
\hline NPU; FP & 10 & 15 & 2 & 46 & 3 & 0 \\
\hline NPU; TN & 53 & 86 & 113 & 41 & 95 & 120 \\
\hline
\end{tabular}


The diagnostic accuracy on each individual component of the urinalysis is shown in Table 3. In general, this accuracy fluctuated depending on the component and the intensity of the dipstick reaction. For example, 41 NPUs tested "moderate" or "large" for blood. All corresponding LPUs were positive for blood: 32 "moderate" or "large," 9 "small" and zero "trace." Sixteen NPUs tested "moderate" or "large" for leukocyte esterase. All corresponding LPUs were positive for leukocyte esterase: 11 "moderate" or "large," 5 "small."

\section{DISCUSSION}

Although urinalysis is a commonly used test in emergency medicine, it has limitations. A negative dipstick urinalysis is probably insufficient to rule out urinary tract infection in adults with 1 or more urinary symptoms. ${ }^{2}$ The same may be true in children $0-2$ years old. The sensitivity and specificity of urinalysis for predicting a positive urine culture will vary considerably based on the definition of a positive urinalysis. ${ }^{4}$ Despite these limitations, the urinalysis does add to clinical assessment in the diagnosis of urinary tract infection. ${ }^{5}$ Physicians also sometimes find urinalysis useful in the evaluation of nontraumatic abdominal pain. ${ }^{6}$

If the urinalysis is to be used in clinical decisionmaking, physicians must decide whether specimens will be sent to the laboratory for analysis. Laboratory analysis will entail some finite delay, but may be more precise when analyzed by machine. However, delays in performing urinalysis can affect results because of cell settling or lysis. ${ }^{7}$ On the other hand, the results of urine dipstick performed by emergency staff are available within minutes. Thus a comparison between methods is relevant.

One previous study, by Kerr and colleagues, ${ }^{1}$ compared 31 urinalyses performed visually by emergency physicians and performed using photometry by laboratory technicians. When compared with the laboratory, emergency physicians were able to identify blood (sensitivity $75 \%$, specificity $82 \%$ ), leukocyte esterase (sensitivity 64\%, specificity 94\%), nitrites (sensitivity $100 \%$, specificity $100 \%$ ) and protein (sensitivity 94\%, specificity $88 \%$ ) only moderately well. It is possible that the greater willingness of emergency nurses to wait the full 2 minutes required to interpret some elements of the dipstick accounted for the improved sensitivity I observed in my sample. Microscopy performed by emergency physicians was much less accurate than microscopy performed by laboratory technicians in this study. ${ }^{1}$
Several other studies address this issue indirectly. A laboratory study by Peele and coworkers ${ }^{8}$ compared visual and photometric readings of prepared and pathologic urines. Photometric readings were more precise for nitrites and protein, but equally precise for ketones. They were more precise for glucose at some concentrations of glucose, but visual readings were more precise at other concentrations. Dipstick tests for blood and leukocyte esterase were not studied in this paper.

A study by Holland colleagues ${ }^{9}$ measured the performance of urine dipsticks, read either visually or by photometry and compared them with a gold standard of culture. Although they were not directly compared, visual reading had a slightly lower sensitivity but slightly higher specificity than photometric reading. All analyses were done in the laboratory.

A small study by Pritchard and Levernier ${ }^{10}$ compared nurse-performed with laboratory-performed urine dipstick tests for leukocyte esterase and nitrites. This study took place in the long-term care setting, and included only men. The results were concordant for leukocyte esterase in $76 \%$, and for nitrites in $97 \%$. Sensitivities and specificities were not reported.

When any abnormality on urinalysis is used as the criterion, I found that an NPU is sensitive, but not specific. This finding supports the use of NPUs as a screening test, followed by LPU to verify positive results. While this would save time and reduce laboratory use, these effects are mitigated by the observation that most of the NPUs in our sample were positive on at least 1 component. Moreover, given this study's small sample size, the CI for the negative predictive value is wide.

Many of the false-positive NPUs in this study were accounted for by samples that the nurse interpreted as "trace" positive. This suggests that, when in doubt, the nurse is likely to record the result as trace positive rather than negative. In contrast, all urine specimens in this study for which the emergency nurse identified "moderate" or "large" amounts of blood or of leukocyte esterase were subsequently confirmed by the laboratory. This suggests that the physicians could act on these findings without waiting for the LPU. Again, a larger study would be needed to confirm this hypothesis.

\section{Limitations}

This study suffers from several limitations. First, the overall number of specimens was small. Second, this was a convenience sample from the clinical practice of a single physician at a single centre. Third, it was not 
possible to consider microscopy in this analysis, as no microscope was available in the ED. Finally, no formal training was implemented for the emergency nurses performing NPUs.

\section{CONCLUSION}

Emergency physicians should not assume that a dipstick urinalysis performed in the ED is equivalent to laboratory urinalysis. Despite this, a completely negative dipstick interpreted by an emergency nurse is almost always negative when repeated by the laboratory, rendering this second step unnecessary in most cases. On the other hand, any positive finding on initial dipstick should be interpreted with caution given the poor specificity, and laboratory testing should be considered to verify these results.

Acknowledgements: The author thanks the nurses and laboratory technicians of the Cornwall Community Hospital who performed and interpreted the urinalyses.

Competing interests: None declared.

\section{REFERENCES}

1. Kerr S, Marshall C, Sinclair D. Emergency physicians versus laboratory technicians: Are the urinalysis and microscopy results comparable? A pilot study. 7 Emerg Med 1999;17: $399-404$.

2. Ohly N, Teece S. Accuracy of negative dipstick urine analysis in ruling out urinary tract infection in adults. Emerg Med J 2003;20:362-3.

3. Doley A, Nelligan M. Is a negative dipstick urinalysis good enough to exclude urinary tract infection in paediatric emergency department patients? Emerg Med (Fremantle) 2003;15: 77-80.

4. Lammers RL, Gibson S, Kovacs D, et al. Comparison of test characteristics of urine dipstick and urinalysis at various test cut off points. Ann Emerg Med 2001;38:505-12.

5. Sultana RV, Zalstein S, Cameron P, et al. Dipstick urinalysis and the accuracy of the clinical diagnosis of urinary tract infection. J Emerg Med 2001;20:13-9.

6. Nagurney JT, Brown D, Chang Y, et al. Use of diagnostic testing in the emergency department for patients presenting with non-traumatic abdominal pain. 7 Emerg Med 2003;25:363-71.

7. Dean A, Lee D. Bedside laboratory and microbiologic procedures. In: Roberts J, Hedges J, editors. Clinical procedures in emergency medicine, 4th ed. Philidelphia (PA): Saunders; 2004. p. 1392-9.

8. Peele JD, Gadsden R, Crews R. Semi-automated vs. visual reading of urinalysis dipsticks. Clin Chem 1977;23:2242-5.

9. Holland DJ, Bliss KJ, Allen CD, et al. A comparison of chemical dipsticks read visually or by photometry in the routine screening of urine specimens in the clinical microbiology laboratory. Pathology 1995;27:91-6.

10. Pritchard V, Levernier J. Multistix versus laboratory urinalysis in the detection of urinary tract infection. 7 Gerontol Nurs $1991 ; 17: 39-42$.

Correspondence to: Dr. James Worrall, Department of Emergency Medicine, Cornwall Community Hospital, 840 McConnell Ave., Cornwall ON K6H 5S5; jworrall@rogers.com 